DOI: https://doi.org/10.24127/ajpm.v9i1.2597

\title{
OPTIMALISASI RENCANA PEMASANGAN KABEL FIBER OPTIC DI ITERA DENGAN ALGORITMA PRIM
}

\author{
Dewi Suhika ${ }^{1}$, Triyana Muliawati ${ }^{2}$, Heru Ruwandar ${ }^{3}$ \\ ${ }^{1,2,3}$ Institut Teknologi Sumatera, Lampung, Indonesia \\ E-mail: $\quad$ dewi.suhika@ma.itera.ac.id ${ }^{1)}$ \\ triyana.muliawati@ma.itera.ac.id ${ }^{2)}$ \\ heru.ruwandar@staff.itera.ac.id $^{3}$ )
}

Received 08 January 2020; Received in revised form 01 February 2020; Accepted 28 March 2020

\begin{abstract}
Abstrak
Kabel fiber optic (FO) digunakan sebagai tulang punggung jaringan komputer Institut Teknologi Sumatera (ITERA). Salah satu perencaannya adalah dengan mengukur jarak antar gedung yang akan ditarik kabel FO. Tujuan dari penelitian ini adalah mengetahui bentuk graf pada jaringan kabel FO dan mengetahui jarak terpendek antar gedung, sehingga dapat meminimalkan biaya dalam pemasangan kabel FO di ITERA dengan menggunakan algoritma Prim. Algoritma Prim digunakan untuk mencari jarak terpendek dari sebuah graf yang telah dimodelkan dengan memberi bobot pada jarak antar gedung sehingga membentuk suatu graf berbobot yang kemudian ditentukan Minimum Spanning Tree (MST). MST merupakan masalah optimasi yang bertujuan mencari Spanning Tree dengan jumlah bobot paling kecil dari sebuah graf. Hasil penelitian menunjukan jika menggunakan algoritma Prim diperoleh minimum spanning tree dengan total jarak 16.503 meter, dari graf awal ada 88 titik dan 84 sisi dengan total panjang jaringan 18.448 meter. Ada perbedaan total jarak yaitu 1945 meter, sehingga dapat disimpulkan bahwa algoritma Prim dapat digunakan sebagai metode untuk menemukan jaringan yang optimal pada jaringan FO ITERA.
\end{abstract}

Kata kunci: algoritma Prim; fiber optic; graf; graf berbobot; minimum spanning tree.

\begin{abstract}
Fiber optic cable (FO) is used as the backbone of the ITERA computer network. One of the plans is to measure the distance between buildings that will be pulled by FO cables. The purpose of this study is to determine the shape of the graph on the FO cable network and find out the shortest distance between buildings, so as to minimize the cost of FO cable installation at ITERA by using Prim's algorithm. Prim's algorithm is used to find the shortest distance from a graph that has been modeled by giving weight to the distance between buildings to form a weighted graph which is then determined its Minimum Spanning Tree. MST is an optimization problem that aims to find the Spanning Tree with the smallest number of weights from a graph. The results of this research are expected to provide input for the design of FO cable cabling at ITERA, so the costs incurred can be more efficient. The results showed that if using Prim algorithm obtained a minimum spanning tree with a total distance of 16,503 meters, from the initial graph there were 88 points and 84 sides with a total network length of 18,448 meters. There is a difference in the total distance of 1945 meters, so it can be concluded that the Prim algorithm can be used as a method for finding the optimal network on the ITERA FO network.
\end{abstract}

Keywords: fiber optic, graph, minimum spanning tree, Prim's algorithm, weighted graph.

\section{PENDAHULUAN}

Kebutuhan akan akses informasi terus bertambah. Kegiatan belajar mengajar juga banyak menggunakan media online dalam pembelajarannya. Untuk memenuhi kebutuhan tersebut dibangunlah infrastruktur jaringan komputer yang sejalan dengan pembangunan infrastruktur gedung dan jalan kampus ITERA. Kabel serat optik (fiber optic/FO) digunakan sebagai tulang punggung (back bone) jaringan komputer ITERA sesuai dengan masterplan pengembangan infrastruktur 
ITERA (Yunmar dkk, 2017). Fiber optic memiliki kecepatan transfer yang sangat tinggi karena menggunakan gelombang cahaya.

Berdasarkan pertimbangan inilah mengapa ITERA menggunakan fiber optic sebagai media utama untuk menunjang komunikasi backbone jaringan komputer ITERA. Oleh karena itu, perlu dilakukan perencanaan yang matang agar didapatkan hasil yang efektif dan efisien. Salah satu perencaannya adalah dengan mengukur jarak antar gedung yang akan ditarik kabel FO, kemudian dicari jalur terpendek agar pemasangan kabel FO lebih optimal.

Secara matematis, gedung-gedung dan kabel FO di ITERA dapat dimodelkan dengan graf dimana gedung-gedung digambarkan sebagai simpul (vertex) dan kabel FO digambarkan sebagai sisi (edge) yang menghubungkan simpul-simpul tersebut. Dalam penelitian ini dijelaskan tentang penerapan Algoritma Prim pada jaringan kabel FO di ITERA sehingga diperoleh panjang kabel yang minimum. Algoritma prim digunakan untuk mencari jarak terpendek dari sebuah graf yang telah dimodelkan dengan memberi bobot pada jarak antar gedung sehingga membentuk suatu graf berbobot yang kemudian ditentukan Minimum Spanning Tree-nya (Ramadhan dkk, 2018). Minimum Spanning Tree (MST) merupakan masalah optimasi yang bertujuan mencari Spanning Tree dengan jumlah bobot paling kecil dari sebuah graf (Suhika \& Wamiliana, 2018).

Pada penelitian Triami, Yundari \& Fan (2020) membahas tentang MST pada jaringan fiber optic di Universitas Tanjungpura menggunakan algorima Prim, algoritma Kruskal, dan algoritma Sollin. Dalam penelitiannya dibahas mengenai penerapan beberapa algoritma sebagai alternatif mendapatkan MST pada jaringan fiber optic di Universitas Tanjungpura. Abrori \& Ubaidillah (2014) mengkaji masalah optimalisasi jaringan kabel FO di Universitas Islam Indonesia menggunakan MST. Penelitian tersebut menggunakan 4 algoritma, yaitu algoritma Kruskal, Prim, Boruvka dan algoritma Solin untuk menemukan MST. Hasil pengamatan yang dilakukan, diketahui bahwa jaringan komputer yang ada di kampus terpadu UII memiliki panjang kabel 6.120 meter dan panjang lintasan 2.050 meter.

Penelitian-penelitian sebelumnya yang membahas tentang algoritma Prim yaitu Prasetyo, Suyitno, \& Mashuri (2013) dalam penelitiannya menggunakan algoritma Prim untuk menyelesaikan masalah optimalisasi pendistribusian air. Kesimpulan dari penelitian tersebut adalah algoritma Prim dapat dijadikan bahan evaluasi untuk jaringan pipa yang telah terpasang (Prasetyo, Suyitno, \& Mashuri, 2018). Penelitian lainnya adalah terkait masalah visualisasi minimum spanning tree menggunakan algoritma Prim (Amin, 2014), yaitu melakukan Analisa pada salah satu bentuk graf pohon, khususnya pada pembentukan MST. Penelitian ini menggunakan algortima Prim untuk mencari jalur terpendek berdasarkan perhitungan matematis yang nantinya dipakai untuk mencari rute jaringan komputer yang dilakukan oleh UPT TIK dalam mencari jalur terpendek pemasangan kabel FO.

Berdasarkan latar belakang, maka tujuan dari penelitian ini adalah mengetahui bentuk graf pada jaringan kabel FO di ITERA dan mengetahui jarak terpendek antar gedung, sehingga dapat meminimalkan biaya dalam 
DOI: https://doi.org/10.24127/ajpm.v9i1.2597

pemasangan kabel FO di ITERA dengan menggunakan algoritma prim. Penelitian ini diharapkan dapat membantu pembangunan infrastruktur FO di ITERA.

\section{METODE PENELITIAN}

Penelitian ini dilaksanakan di Institut Teknologi Sumatera (ITERA) pada Januari sampai dengan Oktober 2019. Pengumpulan data yaitu berupa data jarak antar gedung yang diketahui melalui masterplan ITERA yang akan digunakan untuk merancang model graf sesuai dengan data yang diperoleh, kemudian dari graf tersebut diberi bobot masing-masing berupa jarak antar gedung sehingga menjadi graf berbobot.

Analisa dalam penelitian ini menggunakan algoritma Prim untuk mencari jalur terpendek dari graf berbobot pada pemasangan kabel FO di ITERA, yang kemudian dihitung jaraknya secara manual.

Algoritma Prim ditemukan oleh Robert C. Prim pada tahun 1957. Algoritma ini membentuk pohon perentang minimum langkah per langkah yang diambil sisi yang paling minimum.

Secara umum tahapan penelitian diuraikan pada langkah-langkah sebagai berikut:

1. Pengumpulan data berupa jarak antar gedung-gedung berdasarkan masterplan ITERA.

2. Membuat sebuah graf jaringan fiber optic ITERA

3. Membuat sebuah pohon yang terdiri dari satu simpul (node), dipilih secara acak dari graf yang dimodelkan.
4. Membuat sebuah himpunan yang berisi semua cabang di graf.

5. Loop sampai semua cabang di dalam himpunan menghubungkan dua simpul di pohon

a. Hapus dari himpunan satu cabang dengan bobot terkecil yang menghubungkan satu simpul di pohon dengan satu simpul di luar pohon.

b. Hubungkan cabang tersebut ke pohon. (Nugraha, 2011).

Hasil penelitian ini diharapkan bisa memberikan masukan untuk perancangan pemasangan kabel $\mathrm{FO}$ di ITERA, sehingga biaya yang dikeluarkan dapat lebih efisien.

\section{HASIL DAN PEMBAHASAN}

Dalam penelitian ini dicari jarak terpendek dari pemasangan kabel fiber optic di ITERA dari satu gedung ke semua gedung yang lainnya dengan menggunakan algoritma Prim. Berdasarkan masterplan ITERA dibuat jaringan kabel fiber optic sehingga diperoleh data jarak antar gedunggedung di ITERA yang kemudian dibuat Graf dari masterplan tersebut. Dari hasil pengukuran jarak antar gedung tersebut diperoleh Graf berbobot. Graf berbobot adalah graf yang setiap sisinya diberi sebuah harga atau bobot. Bobot pada setiap sisi dapat berbeda-beda bergantung pada masalah yang dimodelkan dengan graf (Hayu, Yuliani, \& Sam, 2017).

Masterplan jaringan fiber optic ITERA ditunjukkan pada Gambar 1. 
DOI: https://doi.org/10.24127/ajpm.v9i1.2597

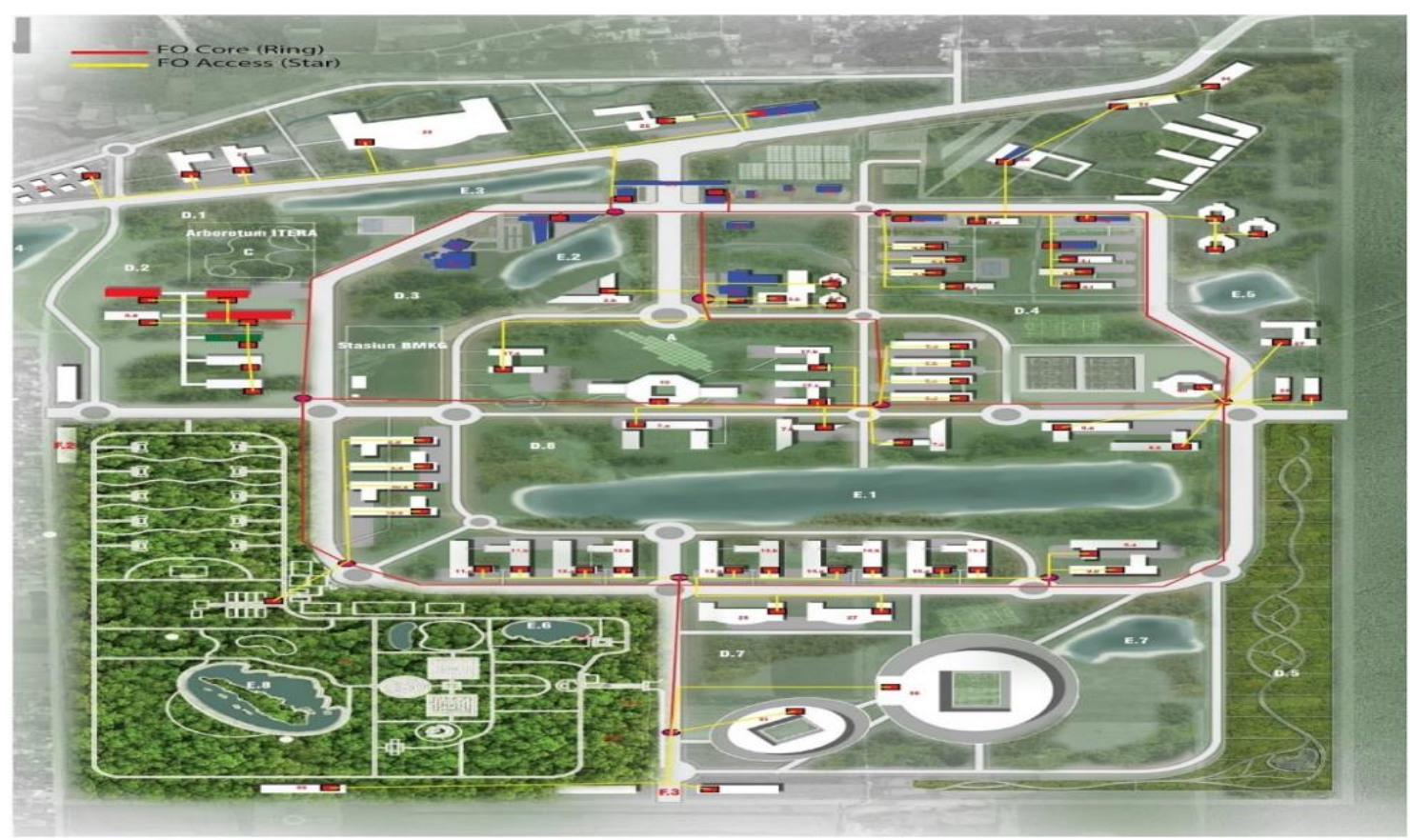

Gambar 1. Masterplan Jaringan Fiber Optik ITERA.

Berdasarkan masterplan FO $v 1, v 2, v 3, \ldots, v 84$ dan sisi (edge) yaitu ITERA, kemudian ditentukan titik jarak antar gedung dinotasikan dengan (vertex) yaitu gedung-gedung yang $e 1, e 2, \ldots, e 88$ seperti pada Gambar 2. dinotasikan dengan angka

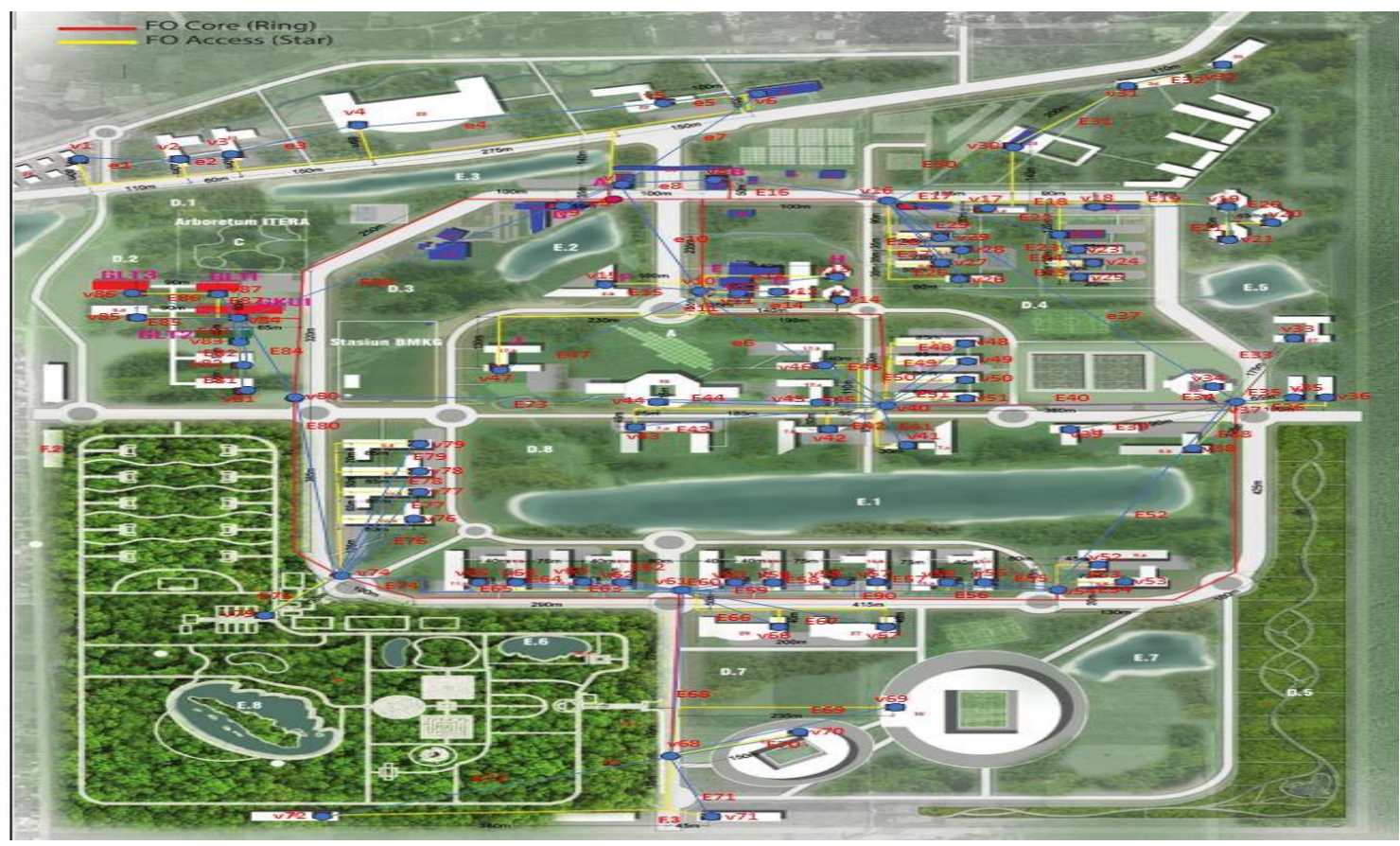

Gambar 2. Masterplan jaringan fiber optic ITERA yang ditentukan vertex dan edge. 
DOI: https://doi.org/10.24127/ajpm.v9i1.2597

Berdasarkan Gambar 2, kemudian dilakukan pengukuran jarak antar gedung sehingga diperoleh data jarak antar gedung seperti pada Gambar 3. Dari data dapat diketahui bahwa jumlah titik (vertex) yang membentuk jaringan kabel fiber optic ITERA berjumlah 88 titik dan memiliki 84 sisi (edge), dengan total jarak 18.448 meter. Berdasarkan masterplan jaringan fiber optic tersebut diperoleh Graf seperti pada Gambar 3.

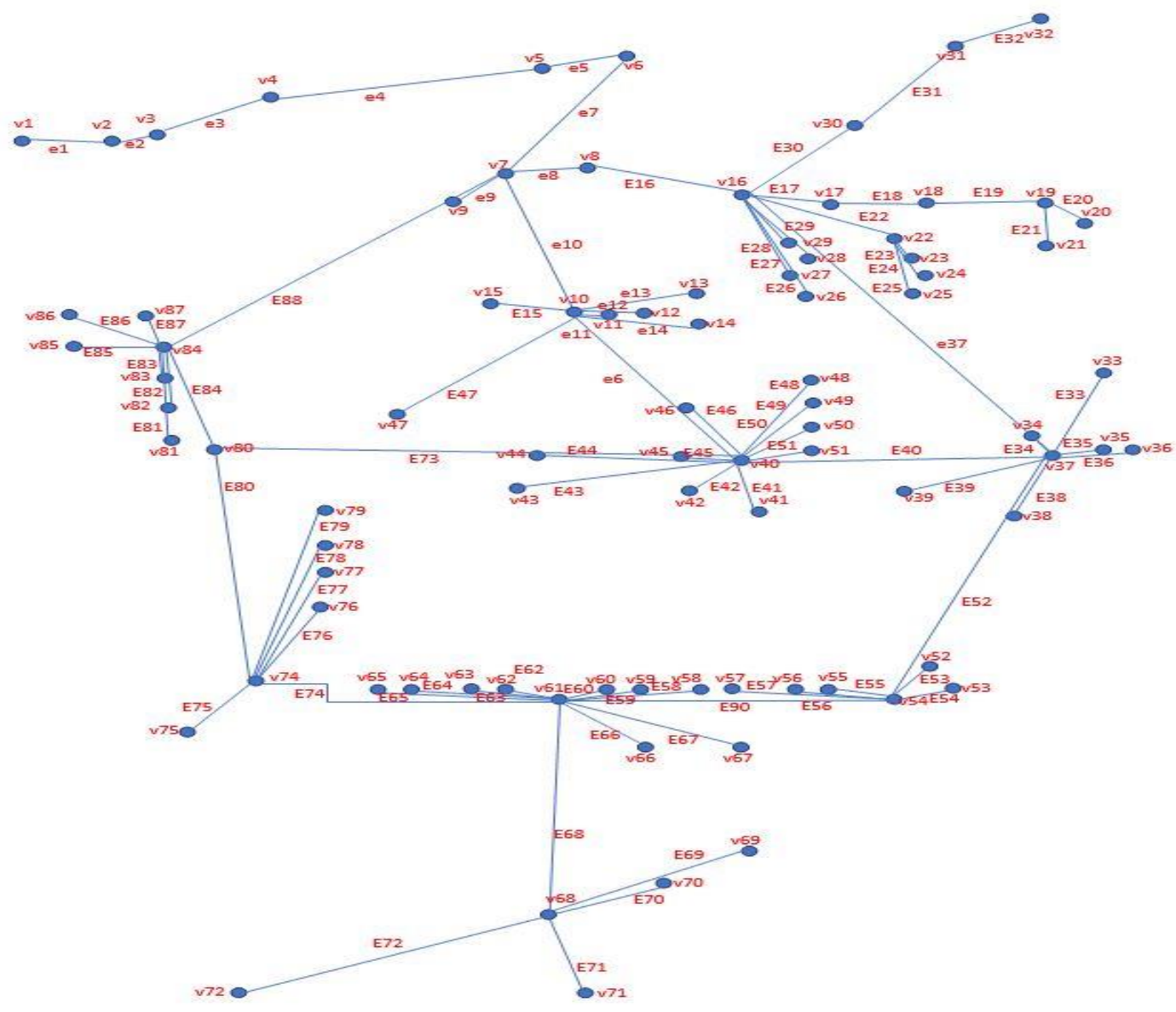

Gambar 3. Graf jaringan fiber optik ITERA

Hasil di atas masih berupa Graf jaringan fiber optic yang memuat sirkuit yang belum ditentukan MST-nya. Masalah MST bertujuan untuk menghubungkan seluruh vertex dalam jaringan sehingga total panjang cabang tersebut dapat diminimumkan. (Kismanti \& Mukhlash, 2017).

Tahap selanjutnya berdasarkan data dan hasil jaringan graf tersebut akan dicari minimum spanning tree dengan menggunakan algoritma Prim sebagai berikut.

Iterasi 1 pilih sisi dengan bobot yang paling kecil yang terhubung dengan $v 1$ dan tidak membentuk sirkuit, karena hanya ada satu sisi yang berhubungan dengan $v 1$ maka dipilih $v 1$ ke $v 2$ dengan bobot 210 meter. Proses Iterasi dilakukan sampai selesai sampai 
DOI: https://doi.org/10.24127/ajpm.v9i1.2597

membentuk minimum spanning tree. (Latifah, U. \& E. Sugiharti, 2015).

Setelah dilakukan perhitungan maka didapatkan graf baru seperti Gambar 4. dengan menggunakan Algoritma Prim,

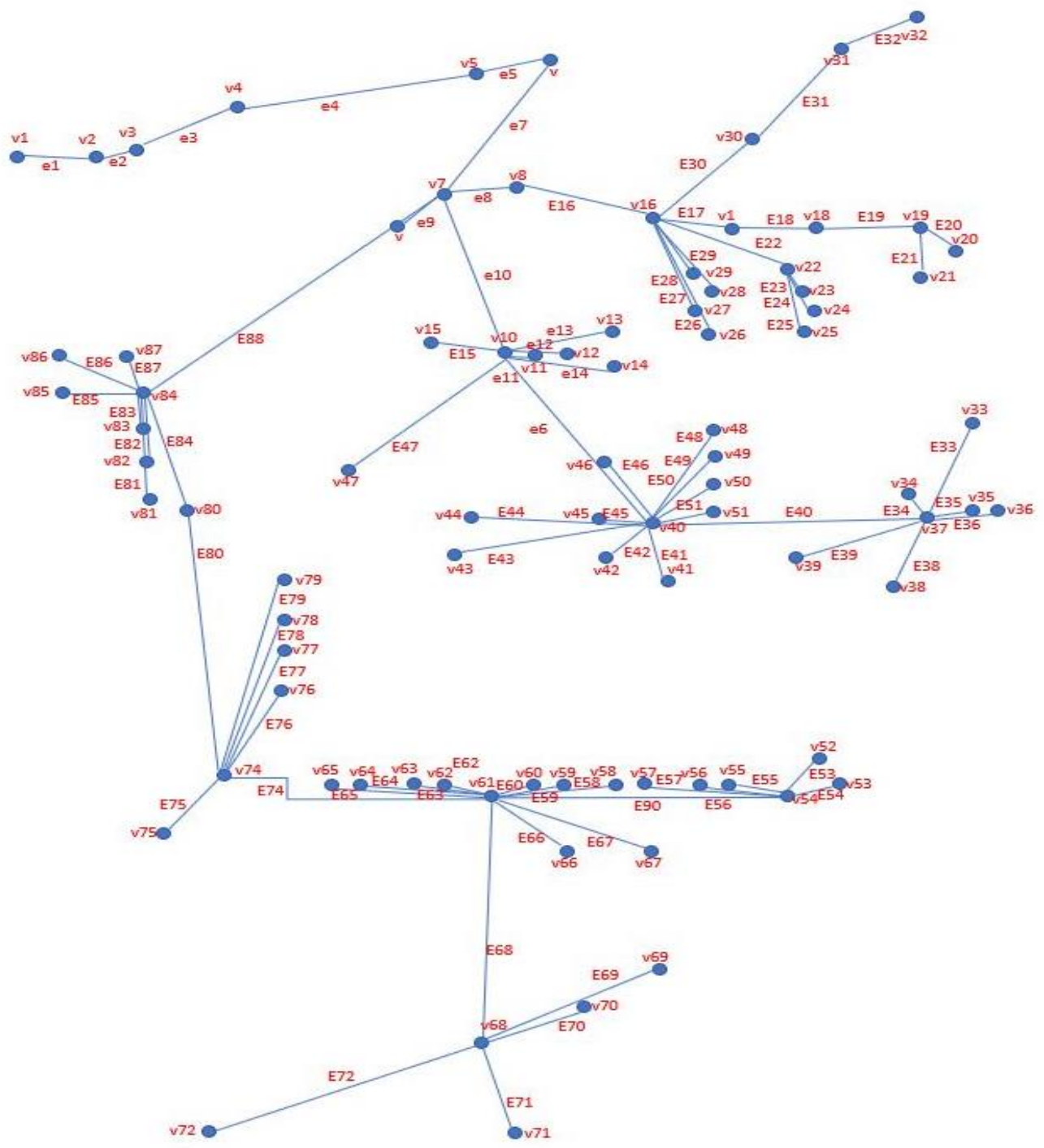

Gambar 4. Graf baru setelah menggunakan algoritma Prim.

Hasil perhitungan berdasarkan data yang didapatkan dengan menerapkan algoritma Prim memberikan hasil pemasangan kabel FO yang lebih optimal dari sisi jarak yaitu diperoleh total jarak 16503 meter.

Graf yang ditampilkan dengan menerapkan algoritma Prim menghasilkan selisih total jarak 1945 meter. Implikasi dari penelitian ini yaitu dengan lebih optimalnya jaringan fiber optic berarti dapat menghemat biaya operasionalnya juga sehingga diharapkan biaya yang dapat dihemat tersebut bisa digunakan untuk keperluan pemasangan kabel fiber optic di ITERA.

\section{KESIMPULAN DAN SARAN}

Berdasarkan hasil penelitian dapat disimpulkan bahwa algoritma Prim dapat digunakan sebagai metode untuk menemukan jaringan yang 
optimal pada jaringan FO ITERA sehingga dapat meminimalkan biaya pemasangan kabel FO.

Dari hasil penelitian yang telah dilakukan bisa dikembangkan lagi mengunakan software Matlab sebagai alat pembanding hasil perhitungan jarak pada permasalahan MST. Selain itu, bisa memodifikasi algoritma Prim atau mencoba algotritma lain yang bisa menghasilkan nilai yang lebih optimal lagi.

\section{DAFTAR PUSTAKA}

Abrori, M. \& Ubaidillah, N. (2014). Pengujian Optimalisasi Jaringan Fiber Optic di Universitas Islam Indonesia Menggunakan Minimum Spanning Tree. Journal Fourier 3(1), 49-58.

Amin, H.I. (2014). Visualisasi Pohon Rentang Minimum Menggunakan Algoritma Kruskal dan Prim. Jurnal Dinamika Teknik 8(1), 4453.

Hayu, W., Yuliani, \& Sam, M. (2017). Pembentukan Pohon Merentang Minimum Dengan Algoritma Kruskal. Journal Scientific Pinisi 3(2), 108-115.

Kismanti, S. T., \& Mukhlash, I. (2017). Penyelesaian Minimum Spanning Tree Dengan Algoritma Berbasis Soft Computing dan Aplikasinya Pada Masalah Logistik.Jurnal Borneo Saintek 1(1), 1-12.

Nugraha, W., D. (2011). Aplikasi Algoritma Prim Untuk Menentukan Minimum Spanning Tree Suatu Graf Berbobot Dengan Menggunakan Pemrograman Berorientasi Objek. Jurnal Ilmiah Foristek 1(2), 70-79.

Prasetyo, V.Z., A. Suyitno, \& Mashuri (2013). Penerapan Algoritma Dijkstra dan Prim pada Pendistribusian Air di PDAM
Kabupaten Demak. UNNES Journal of Mathematics 2(1), 7078.

Prasetyo, V.Z., A. Suyitno, \& Mashuri (2018). Penerapan Algoritma Kruskal dan Sollin Pada Pendistribusian Air PDAM Tirta Aji Cabang Wonosobo dan Penggunaan Microsoft VB 6.0 Sebagai Pembandingnya. UNNES Journal of Mathematics 2(2), , 7078.

Ramadhan, Z., Zarlis, M., Efendi, S., \& Siahaan, A.P.U. (2018). Perbandingan Algoritma Prim dengan Algoritma FloydWarshall dalam Menentukan Rute Terpendek (Shortest Path Problem). Jurnal Riset Komputer (JURIKOM) 5(2), 130-139.

Suhika, D. \& Wamiliana. (2018). Penggunaan Metode Cutting Plane untuk Menyelesaikan Minimum Spanning Tree dengan Kendala Bobot Pada Graf Kn. AKSIOMA: Jurnal Program Studi Pendidikan Matematika 7(1), 87-95.

Latifah, U. \& E. Sugiharti. (2015). Penerapan Algoritma Prim dan Kruskal pada Jaringan Distribusi Air PDAM Tirta Moedal Cabang Semarang Utara. UNNES Journal of Mathematics 4(1), 47-57.

Triami, N.J., Yundari., Fan, F. (2020). Minimum Spanning Tree Pada Jaringan Fiber Optic Di Universitas Tanjungpura. Buletin Ilmiah Math, Stat, dan Terapannya (Bimaster) 9(1), 223230.

Yunmar, R.A. dkk. (2017). Masterplan Pengembangan Teknologi Informasi dan Komunikasi Institut Teknologi Sumatera 2017-2027. UPT TIK, Institut Teknologi Sumatera. 